\title{
The Novel Gluconeogenesis Inhibitor FR225654 that Originates from Phoma sp. No. 00144
}

\section{Structure Determination}

\author{
Yoshihiro Ohtsu $^{\dagger}$, Seiji Yoshimura ${ }^{\dagger}$, Takayoshi Kinoshita ${ }^{\dagger \dagger}$, Shigehiro Takase ${ }^{\dagger}$, \\ Hidenori Nakajima ${ }^{\dagger}$
}

Received: March 29, 2005 / Accepted: June 29, 2005

(C) Japan Antibiotics Research Association

\begin{abstract}
A novel gluconeogenesis inhibitor, FR225654 was isolated from the culture broth of Phoma sp. No. 00144. Spectroscopic analysis concluded that FR225654 has a highly oxygenated trans-decalin ring and $\beta$-keto-enol in its main part, and has a characteristic side chain possessing a conjugated carboxylic acid and tri-substituted olefin.
\end{abstract}

Keywords gluconeogenesis, hepatocyte, diabetes, FR225654

At present, 135 million people are suffering from diabetes in the world, and the number is still increasing. While the cause of diabetes still remains unclear, it is certain that high blood glucose levels damage various human tissues, leading to complications such as neuropathy, retinopathy and kidney diseases. Thus, control of blood glucose levels is a prerequisite for diabetes patients. By assuming that gluconeogenesis inhibitors might be useful for downregulation of blood glucose, we screened for those inhibitors from microbial metabolites and discovered FR225654 in a cultured broth of Phoma sp. No. 00144 [1,
2]. Herein, the structure determination of FR225654 is discussed.

In the negative ESI-MS spectrum, a deprotonated ion of FR225659 (1) was observed at $m / z 507[\mathrm{M}-\mathrm{H}]^{-}$. Elemental analysis and number of carbon atoms deduced from ${ }^{13} \mathrm{C}$ NMR concluded its molecular formula to be $\mathrm{C}_{27} \mathrm{H}_{40} \mathrm{O}_{9}$ (calcd. for $\mathrm{C}_{27} \mathrm{H}_{40} \mathrm{O}_{9} \cdot 1 / 2 \mathrm{H}_{2} \mathrm{O}$ C $62.65, \mathrm{H} 7.98$; found $\mathrm{C}$ 62.22, $\mathrm{H}$ 7.97). IR bands ( $\mathrm{KBr})$ at 3480 (br)/1710 (vs) and $1730(\mathrm{~m}) \mathrm{cm}^{-1}$ were indicative of a carboxyl and an ester function, respectively. Since 1 was unstable in methanol- $d_{4}$, and gave complicated signals due to two tautomeric forms in DMSO- $d_{6}$, we screened deuterated solvents for a series of NMR measurement of $\mathbf{1}$, and found $\mathrm{CD}_{3} \mathrm{CN}$ to be suitable for this purpose. The ${ }^{1} \mathrm{H}$ NMR spectrum in $\mathrm{CD}_{3} \mathrm{CN}$ clearly showed 37 protons including an enol proton $\left(\delta_{\mathrm{H}} 15.0\right)$, three olefinic ones and four singlet methyl groups. In addition, extremely broadened three proton signals were observed in the area of 5.5 3.5 ppm, and assigned as exchangeable. A pair of protons assigned to a disubstituted olefin resonates at 7.77 (d, $J=5 \mathrm{~Hz})$ and $5.98(\mathrm{~d}, J=5 \mathrm{~Hz}) \mathrm{ppm}$, of a highly polarized olefin. The ${ }^{13} \mathrm{C}$ NMR and HSQC spectra in $\mathrm{CD}_{3} \mathrm{CN}$ showed six methyl, five methylene, eight methine and eight quaternary carbons. Signals for a saturated ketone $\left(\delta_{\mathrm{C}}\right.$
S. Yoshimura (Corresponding author): Medicinal Chemistry Research Laboratories, Fujisawa Pharmaceutical Co., Ltd., Email: seiji.yoshimura@jp.astellas.com

Y. Ohtsu, H. Nakajima: Fermentation Research Laboratories, Fujisawa Pharmaceutical Co., Ltd.

T. Kinoshita, S. Takase: Exploratory Research Laboratories, Fujisawa Pharmaceutical Co., Ltd.
${ }^{\dagger}$ Present address: Astellas Pharma. Inc., 5-2-3 Tokodai, Tsukuba, Ibaraki 300-2698, Japan

${ }^{\dagger}$ Present address: Osaka Prefecture University, 1-1 Gakuen-cho, Sakai, Osaka 599-8531, Japan 

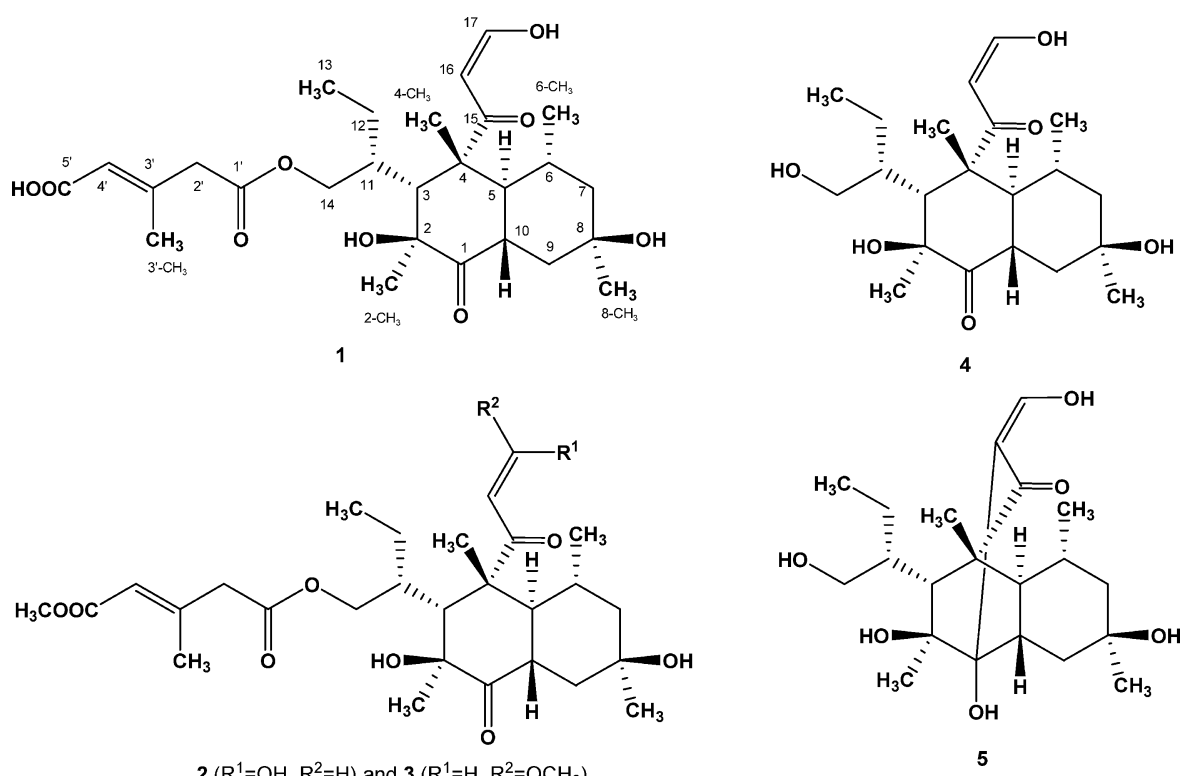

Fig. 1 Structures of FR225654 (1) and its derivatives.

217.4), an unsaturated ketone $\left(\delta_{\mathrm{C}} 209.3\right)$, two more carbonyl carbons $\left(\delta_{\mathrm{C}} 170.9\right.$ and 167.5$)$ and four olefinic carbons $\left(\delta_{\mathrm{C}} 173.5(\mathrm{~d}), 153.5(\mathrm{~s}), 119.7\right.$ (d) and 102.7(d)) were observed in the down field area. The signals resonating at 209.3, 173.5 and $102.7 \mathrm{ppm}$ indicate an enol form of $\beta$-ketoaldehyde, which was supported by strong IR absorptions at 1650 and $1620 \mathrm{~cm}^{-1},{ }^{1} \mathrm{H}$ NMR (vide supra), and more elaborate NMR elucidation (vide infra). Treatment of 1 with a controlled amount of $\mathrm{TMSCHN}_{2}$ yielded the methyl ester 2, and excess of the reagent allowed methylation of the enol to give $\mathbf{3}$, which confirmed the presence of the carboxylic acid and the $\beta$-ketoaldehyde. Three $s p^{3}$ carbons should be oxygenated judging from their chemical shifts $(78.1,69.6$ and $68.9 \mathrm{ppm})$. These partial structures thus account for six of the eight unsaturation degrees required for the molecular formula of $\mathbf{1}$, and this suggested that 1 contains a bicyclic structure.

Analysis of COSY data allowed junctions shown as bold lines in Fig. 2. Further elucidation was carried out mainly using HMBC spectra. In order to connect the quaternary carbons with the other substructures, we first analyzed HMBC correlations from the four singlet methyl protons. HMBC correlation from $8-\mathrm{CH}_{3}$ to $\mathrm{C}-7, \mathrm{C}-8$ and $\mathrm{C}-9$ allowed connections of $8-\mathrm{CH}_{3} / \mathrm{C}-8, \mathrm{C}-7 / \mathrm{C}-8$ and C-8/C-9. Similarly, linkages around C-2, C-4 and C-3' were deduced from HMBC correlations from 2- $\mathrm{CH}_{3}, 4-\mathrm{CH}_{3}$ and $3^{\prime}-\mathrm{CH}_{3}$, respectively. $\mathrm{HMBC}$ correlation from $5-\mathrm{H}, 9 \mathrm{~b}-\mathrm{H}$ and $10-\mathrm{H}$ to $\mathrm{C}-1$ shows $\mathrm{C}-1$ is adjacent to $\mathrm{C}-10$, completing the decalin ring. HMBC data of $16-\mathrm{H} / \mathrm{C}-15$ and $17-\mathrm{H} / \mathrm{C}-15$ indicate the $\beta$-ketoaldehyde structure which links to $\mathrm{C}-4$ of

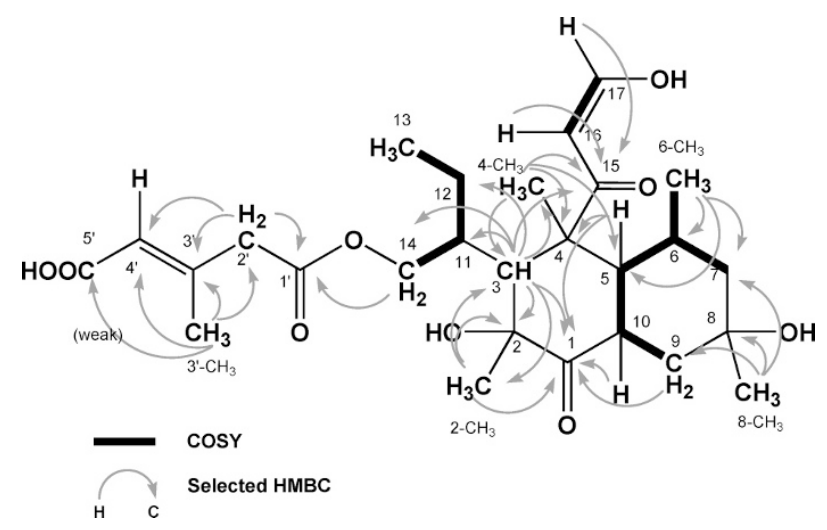

Fig. 2 Structure elucidation of FR225654.

the ring at $\mathrm{C}-15$. The $\mathrm{C}-3 / \mathrm{C}-11$ bond was deduced from HMBC correlations of 3-H/C-11, C-12 and C-14, although the coupling constant of $3-\mathrm{H} / 11-\mathrm{H}$ is almost zero. Weak HMBC correlations of $4^{\prime}-\mathrm{H} / \mathrm{C}-5^{\prime}$ and $3^{\prime}-\mathrm{CH}_{3} / \mathrm{C}-5^{\prime}$ allowed us to establish the linkage of $\mathrm{C}-4^{\prime} / \mathrm{C}-5^{\prime}$. Strong HMBC correlation of $2^{\prime}-\mathrm{H}_{2} / \mathrm{C}-1^{\prime}$ and a weak one of $3^{\prime}-\mathrm{CH}_{3} / \mathrm{C}-1^{\prime}$ unveiled an acyl moiety which could be linked at $\mathrm{C}-1^{\prime}$ to 14-O by HMBC data of $14-\mathrm{H}_{2} / \mathrm{C}-1^{\prime}$. The partial structure thus far accounted for $\mathrm{C}_{27} \mathrm{H}_{36} \mathrm{O}_{9}$ short of four protons of molecular formula of $\mathbf{1}$. The unexplained four protons including the enol one are exchangeable ones, therefore we assigned functionalities of 2-O and 8-O to be hydroxyls, and those of $5^{\prime}-\mathrm{CO}$ and $17-\mathrm{O}$ to be a carboxylic acid and an enol, respectively. The geometry of $\mathrm{C}-16 / \mathrm{C}-17$ was deduced to be $Z$ from the coupling constant of $16-\mathrm{H} / 17-\mathrm{H}$ 
Table 1

\begin{tabular}{|c|c|c|}
\hline \multirow{2}{*}{ Position } & \multicolumn{2}{|c|}{ FR225654 (1) } \\
\hline & $\delta_{\mathrm{H}}\left(\mathrm{CD}_{3} \mathrm{CN}\right)^{\mathrm{a})}$ & $\delta_{\mathrm{C}}\left(\mathrm{CD}_{3} \mathrm{CN}\right)^{\mathrm{a})}$ \\
\hline 1 & & 217.4 \\
\hline 2 & & 78.1 \\
\hline 3 & 1.85 (1H, brs) & 50.5 \\
\hline 4 & & 50.2 \\
\hline 5 & $2.52(1 \mathrm{H}, \mathrm{dd}, 13 \& 10)$ & 45.8 \\
\hline 6 & $1.80(1 \mathrm{H}, \mathrm{m})$ & 30.0 \\
\hline \multirow[t]{2}{*}{7} & $1.50(1 \mathrm{H}, \mathrm{m})$ & 48.4 \\
\hline & $1.12(1 \mathrm{H}, \mathrm{dd}, 14 \& 12)$ & \\
\hline 8 & & 68.9 \\
\hline \multirow[t]{2}{*}{9} & $2.18(1 \mathrm{H}, \mathrm{m})$ & 41.9 \\
\hline & $1.27(1 \mathrm{H}, \mathrm{m})$ & \\
\hline 10 & $2.63(1 \mathrm{H}, \mathrm{m})$ & 41.3 \\
\hline 11 & $2.02(1 \mathrm{H}, \mathrm{m})$ & 41.5 \\
\hline \multirow[t]{2}{*}{12} & $1.52(1 \mathrm{H}, \mathrm{m})$ & 22.5 \\
\hline & $1.37(1 \mathrm{H}, \mathrm{m})$ & \\
\hline 13 & $0.82(3 \mathrm{H}, \mathrm{t}, 7)$ & 13.4 \\
\hline \multirow[t]{2}{*}{14} & $4.22(1 \mathrm{H}, \mathrm{dd}, 10.5,9.5)$ & 69.6 \\
\hline & $4.13(1 \mathrm{H}, \mathrm{dd}, 10.5,4.5)$ & \\
\hline 15 & & 209.3 \\
\hline 16 & $5.98(1 \mathrm{H}, \mathrm{d}, 5)$ & 102.7 \\
\hline 17 & $7.77(1 \mathrm{H}, \mathrm{d}, 5)$ & 173.5 \\
\hline $17-\mathrm{OH}$ & $15.05(1 \mathrm{H}, \mathrm{brs})$ & \\
\hline $2-\mathrm{CH}_{3}$ & $1.54(3 \mathrm{H}, \mathrm{s})$ & 24.6 \\
\hline $4-\mathrm{CH}_{3}$ & $1.27(3 \mathrm{H}, \mathrm{m})$ & 20.6 \\
\hline $6-\mathrm{CH}_{3}$ & $0.69(3 \mathrm{H}, \mathrm{d}, 6.5)$ & 21.3 \\
\hline $8-\mathrm{CH}_{3}$ & $1.16(3 \mathrm{H}, \mathrm{s})$ & 31.0 \\
\hline $1^{\prime}$ & & 170.9 \\
\hline $2^{\prime}$ & $3.16(2 \mathrm{H}, \mathrm{ABq})$ & 46.4 \\
\hline $3^{\prime}$ & & 153.5 \\
\hline $4^{\prime}$ & $5.74(1 \mathrm{H}, \mathrm{brs})$ & 119.7 \\
\hline $5^{\prime}$ & & 167.5 \\
\hline $3^{\prime}-\mathrm{CH}_{3}$ & $2.12(3 \mathrm{H}, \mathrm{brs})$ & 19.1 \\
\hline
\end{tabular}

a) Residual solvent signals are used as internal standards $\left(\delta_{\mathrm{H}} 1.96\right.$ for $\mathrm{C} \underline{H} \mathrm{D}_{2} \mathrm{CN}, \delta_{\mathrm{C}} 118.28$ for $\left.\mathrm{CD}_{3} \underline{\mathrm{CN}}\right)$

$(5 \mathrm{~Hz})$, and that of $\mathrm{C}-3^{\prime} / \mathrm{C}-4^{\prime}$ to be $E$ from NOE of $2^{\prime}-$ $\mathrm{H}_{2} / 4^{\prime}-\mathrm{H}$. Therefore, the planar structure of $\mathbf{1}$ was determined as shown in Fig. 2, and ${ }^{1} \mathrm{H}$ and ${ }^{13} \mathrm{C}$ NMR assignments of $\mathbf{1}$ are depicted in Table 1.

We first examined the stereochemistry of $\mathbf{1}$ using NMR. Stereochemical analyses with NOE values and protonproton coupling constants are summarized in Fig. 3. Observation of a NOE between $5-\mathrm{H} / 7-\mathrm{Hb} / 9 \mathrm{~b}-\mathrm{Hb}$ revealed these protons to be 1,3-diaxial to one another and the conformation of B-ring to be chair-like. This was supported by large coupling constants of 5-H/6-H (13 Hz), 6-H/7-Hb

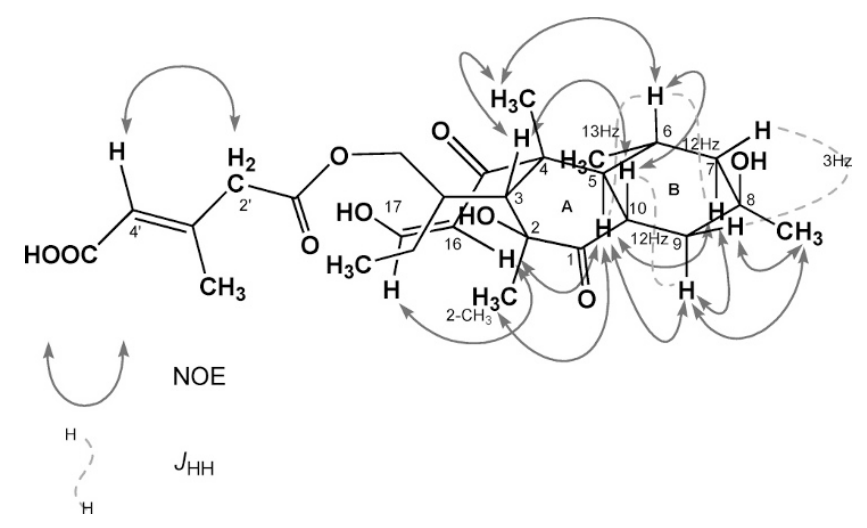

Fig. 3 Stereochemical analysis of FR225654.

(12 Hz), 9-Hb/10-H (12 Hz) and 10-H/5-H $(11 \mathrm{~Hz})$, and by a w-coupling from 1,3-diequatorial of 7-Ha/9-Ha (3 Hz). These coupling constants also show 5- H, 6- $\mathrm{H}, 7-\mathrm{Hb}, 9-\mathrm{Hb}$ and $10-\mathrm{H}$ to be axial, and as can be expected, a NOE from the 1,3-diaxial of $6-\mathrm{H} / 10-\mathrm{H}$ was clearly observed. Thus, it was concluded that the decalin ring is trans-fused, and 6$\mathrm{CH}_{3}$ is equatorial. Orientation of $8-\mathrm{CH}_{3}$ was deduced to be equatorial from NOEs between $8-\mathrm{CH}_{3}$ and $9-\mathrm{H}_{2}$. In the Aring, NOEs of $3-\mathrm{H} / 10-\mathrm{H}$ and $2-\mathrm{CH}_{3} / 5-\mathrm{H}$ were observed from 1,4-diaxial, which positioned this ring in a boat-like form. The keto-enol moiety should orient downward from the boat because of a NOE cross peak of $5-\mathrm{H} / 16-\mathrm{H}$. This was further supported by NOEs of $4-\mathrm{CH}_{3} / 6-\mathrm{H}$ and $3-\mathrm{H} / 4-$ $\mathrm{CH}_{3}$. Thus, the relative configuration of the decalin ring was determined to be as shown in Fig. 3. We resolved the relative stereochemistry at $\mathrm{C}-11$ and the absolute configuration of $\mathbf{1}$ by X-ray crystallography, using fine needles, obtained from hot acetonitrile. The molecule in the crystal, however, proved to be packed to form a large crystal lattice, and thus it was difficult to obtain enough resolution to determine the structure. Since the crystal was not stable enough to collect X-ray diffraction data for a long period, we applied high energy X-ray of BL24XU in Spring8 [3] and finally succeeded in obtaining excellent data to determine the absolute configuration of $\mathbf{1}$. ORTEP drawing of $\mathbf{1}$ is depicted in Fig. 4, and the gross structure including the absolute stereochemistry is unequivocally determined as shown in Fig. 1.

In conclusion, the structure of $\mathbf{1}$ was detemined as shown in Fig. 1 including its absolute stereochemistry. Although compound 1 shares its core structure with stemphyloxin I [4], and betaenone $\mathrm{C}$ [5], it uniquely in that it possesses the unusual side chain flanked with an ester, and such as possesses strong gluconeogenesis inhibitory activity. It is noteworthy that saponification of the ester of $\mathbf{1}$ gave two compounds identical with stemphyloxin I (4) and II (5) (see 


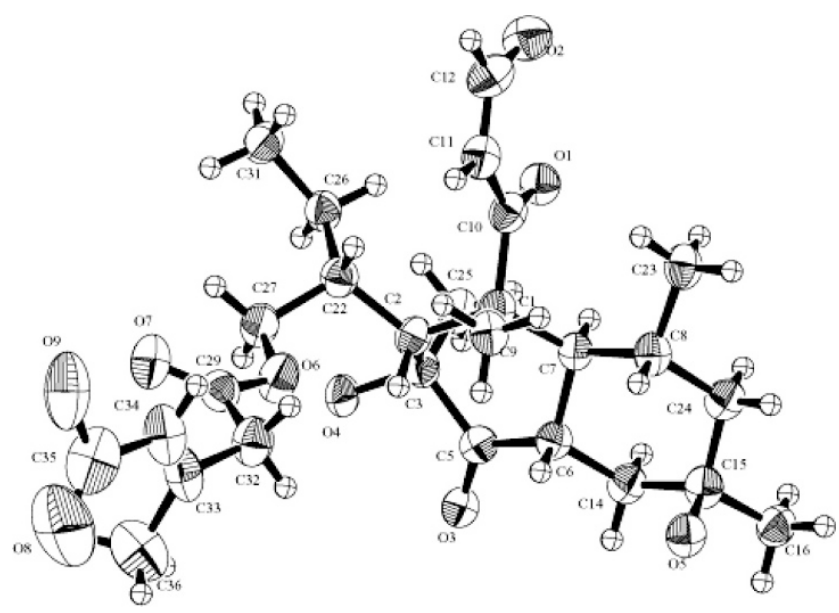

Fig. 4 ORTEP drawing of FR225654 (1).

Fig. 1), both of which show much weaker inhibition against gluconeogenesis than 1 does. With the same screening concept, we isolated FR225659 and its minor congeners before [6]. Interestingly, their structures and biological properties are quite different from those of $\mathbf{1}$. This fact shows that our concept is appropriate for natural products screening and we are currently continuing and developing this study to find other unique gluconeogenesis inhibitors.

Acknowledgement The authors appreciate Spring8 for permitting us to use BL24XU.

\section{References}

1. Ohtsu Y, Sasamura H, Tanaka M, Tsurumi Y, Yoshimura S, Takase S, Shibata T, Hino M, Nakajima H. The novel gluconeogenesis inhibitor FR225654 that originates from Phoma sp. No. 00144 I. Taxonomy, fermentation, isolation and physico-chemical properties. J Antibiot 58: 447-451 (2005)

2. Ohtsu Y, Sasamura H, Shibata T, Hino M, Nakajima H. The novel gluconeogenesis inhibitor FR225654 that originates from Phoma sp. No. 00144 II. Biological activities. J Antibiot 58: 452-455 (2005)

3. http://www.spring8.or.jp/e/

4. Barash I, Manulis S. Crystallization and X-ray analysis of stemphyloxin I, a phytotoxin from Stemphylium botryosum. Science 220: 1065-1066 (1983)

5. Ichihara A, Oikawa H, Hayashi K, Sakamura S. Structures of bataenones A and B, novel phytotoxins from Phoma betae Fr. J Am Chem Soc 105: 2907-2908 (1983)

6. Ohtsu Y, Sasamura H, Tsurumi Y, Yoshimura S, Takase S, Hashimoto M, Shibata T, Hino M, Fujii T. The novel gluconeogenesis inhibitors FR225659 and related compounds that originate from Helicomyces sp. No. 19353. I. Taxonomy, fermentation, isolation and physico-chemical properties. J Antibiot 56: 682-688 (2003) 